\title{
Politik Etnisitas Dalam Upaya Pemekaran Provinsi Kotawaringin
}

\author{
Ricky Zulfauzan $^{1}$, Kris Nugroho ${ }^{2}$, Dwi Windyatuti ${ }^{3}$ \\ Fakultas Ilmu Sosial dan Ilmu Politik, Universitas Airlangga ${ }^{1}$ \\ Departemen Ilmu Politik, Fakultas Ilmu Sosial dan Ilmu Politik, Universitas Airlangga ${ }^{2}$ \\ rickyzulfauzan-2014@fisip.unair.ac.id ${ }^{1}$
}

Diterima: 30/10/2019
Direview: 02/11/2018
Diterbitkan: 30/12/2019
Hak Cipta @ 2019 oleh Penulis (dkk) dan Jurnal
Sosial Humaniora (JSH)
*This work is licensed under the Creative
Commons Attribution International License (CC
BY 4.0).
http://creativecommons.org/licenses/by/4.0/
cC (i) Open Access

\begin{abstract}
Subject Area: Social and Politics (Sosial dan Politik)
Abstract [in ENGLISH]

This study aims to provide a descriptive analysis of ethnicity politics from the perspective of Glazer and Moynihan "Beyond The Melting Pot" to expand Kotawaringin Province. The research method used is qualitative with a case study approach. The research data were obtained from observations, document searches and in-deep interviews. The results found that the desire to separate from Central Kalimantan Province made the five prospective regencies of Kotawaringin Province form a Melting Pot. "Melting Pot," which is meant here, is to be "Orang Kotawaringin." The Kotawaringin community is very heterogeneous, originating from not only one ethnicity but being able to unite for a common goal.

In contrast to Glazer and Moynihan's "Being America," which illustrates the pattern of ethnic interaction in New York City is eternal. In Kotawaringin, this ethnic identity is only temporary and impermanent. The collective identity of being an Orang Kotawaringin is built according to an instrumentalist perspective, namely: ethnicity is seen not only as a given value or as a result of a social construction but rather as used to obtain benefits, including federal benefits.
\end{abstract}

Keywords: Ethnicity Politics; Instrumentalist Perspective; Regional Expansion

\section{Pendahuluan}

Politik identitas dewasa ini menjadi sebuah isu yang mengglobal dalam berbagai tema-tema politik kontemporer (Canessa, 2014; Escárcega, 2010; Hill \& Wilson, 2003). Sejalan dengan itu, Samuel P. Huntington dalam buku yang berjudul The Clash of Civilizations and The Remaking of World Order (1996) pernah menuliskan secara gamblang akan potensi konflik dalam politik domestik dan politik global. Ia memaparkan, setelah jatuhnya Uni Soviet maka potensi konflik global bukan lagi didasari pada ideologi melainkan identitas. Lebih jauh lagi dipaparkannya bahwa suasana politik global akan diwarnai oleh politic of civilization sedangkan politik domestik akan ditandai dengan apa yang disebutnya politic of ethnicity (Huntington, 1997).

Demikian halnya di Indonesia pasca Orde Baru, berkah reformasi politik di Indonesia yang semakin dirasakan oleh masyarakat di penjuru Indonesia adalah menguatnya desentralisasi dalam mewujudkan otonomi daerah yang seluas-luasnya (Prasetyo, 2014). Desefntralisasi dan otonomi daerah ialah suatu konsep dimana hubungan pemerintahan pusat dan pemerintahan daerah yang longgar, dimana pemerintah pusat tidak lagi terlibat banyak dalam urusan pemerintahan daerah. 
Seiring perkembangan politik diawal-awal era reformasi, lebih khusus terkait dengan berlakukannya Undang-undang Nomor 22 Tahun 1999 banyak bermunculan keinginan berbagai daerah untuk memekarkan diri membentuk Daerah Otonom Baru (DOB) (Narang, 2004). Untuk itu pemerintah menerbitkan Peraturan Pemerintah Nomor 129 Tahun 2000 tentang Pemekaran Daerah yang mengatur antara lain tentang instrumen prosedural dan instrumen persyaratan pemekaran daerah.

Sangat besarnya tuntutan dan keinginan setiap daerah untuk memekarkan diri akhirnya menimbulkan berbagai permasalahan (Simanjuntak, 2010). Permasalahan itu seperti munculnya sengketa batas wilayah, konflik etnik, dan oligarki baru. Oleh karena itu maka, Peraturan Pemerintah Nomor 129 Tahun 2000 tentang Pemekaran Daerah direvisi dengan Peraturan Pemerintah Nomor 78 Tahun 2007 tentang Tata Cara Pembentukan, Penghapusan, dan Penggabungan Daerah yang lebih ketat. Peraturan pemerintah tersebut memberikan prasyarat pembentukan wilayah provinsi harus meliputi minimal lima kabupaten atau kota, sedangkan untuk kabupaten terdiri dari lima kecamatan dan kota dengan empat kecamatan.

Pemekaran wilayah yang terjadi di Indonesia menurut Berita Sampit tahun 2018 tidak selalu terjadi karena motif dan pertimbangan seperti lazim dinyatakan dalam dokumen resmi, atau hasil analisis para ahli tentang adanya kepentingan elit lokal melakukan pemekaran daerah untuk menduduki jabatan di kabupaten atau kota atau provinsi pemekaran (Zulfauzan, 2018). Politik etnisitas pun tidak kalah kuat memicu tindakan politik pemekaran daerah. Politik etnisitas dalam hal ini adalah politik yang terjadi dalam interaksi antara dua atau lebih kelompok etnis yang heterogen tetapi hidup bersama di dalam suatu komunitas masyarakat.

Sebagaimana disampaikan oleh Hale (2008) dalam memandang politik etnisitas selama ini: teoritisi selalu memulai diskusi dengan debat antara apa yang disebut dengan primordialisme dan apa yang membuatnya berbeda dengan istilah konstruktivisme, sirkumstansialisme atau instrumentalisme.

Secara khusus Schulte Nordholt dan Klinken (2007) berbicara tentang pemekaran dan etnisitas yang dinamis menyatakan: "Pemekaran after 1998 was largerly driven from below. ...the combination of two essentially different processes-administrative decen-tralization and popular democratization produced much freer competition between local elits for control of the state. They often conducted their competition in ethnic term”.

Berdasakan perspektif primordialis, Qodir (2012)menemukan bahwa peta konstruksi elit tentang pemekaran jauh berbeda dengan konstruksi kaum minoritas dan masyarakat.

Sedikit berbeda dengan Kambo (2007) dan Qodir (2012) berhasil menjelaskan kebangkitan identitas etnik menggunakan perspektif konstruktivis.Melalui kedua hasil temuan penelitian tersebut nampak ada beberapa kelemahan yang dimiliki. Penelitian Qodir dengan perspektif primordialisnya sangat statis dan tak mampu menjelaskan akan kemunculan etnisitas, stabilisasi, serta perubahannya dari waktu ke waktu. Sementara Gustiana dengan perspektif konstruktivis nampak memiliki kelemahan pula yaitu kurang mampu menjelaskan peranan atau motivasi politik dan ekonomi dari setiap individu dalam mengkonstruksi etnisitas.

Untuk menelaah masalah dalam penelitian ini tentu tidak akan mampu terjawab dengan maksimal apabila menggunakan perspektif primordialis dan konstruktivis. Ini dikarenakan melalui penelitian ini peneliti ingin menjelaskan peranan atau motivasi ekonomi dan politik dari individu dalam memandang etnisitas. Semua itu hanya dapat dijawab menggunakan perspektif instrumentalis. 
Sementara itu, usulan pembentukan Daerah Otonom Baru (DOB) Provinsi Kotawaringin Raya ternyata terlihat kecenderungan yang unik. Unik karena sampai sejauh ini para teoritisi ilmu politik yang konsentrasi kajiannya pada politik etnisitas cenderung membagi ini ke dalam dua arus besar pemikiran, yaitu: primordialis elit-elit politik lokal dan konstruksi elit politik lokal. Artinya pembentukan Daerah Otonom Baru (DOB) sejauh ini hanya dilihat dan menghubungkan dua diantara perspektif tersebut.

Penelitian ini melihat politik etnisitas mengunakan perpektif instrumentalis yaitu suatu cara pandang terhadap etnisitas sebagai sebuah instrumen atau alat strategis untuk memperoleh sumber daya. Maksudnya etnisitas dipandang tidak hanya sebagai sebuah nilai yang terberi atau pun hasil dari sebuah konstruksi sosial namun lebih kepada pemanfaatan untuk memperoleh benefit, termasuk benefit politik Tujuan penelitian ini adalah untuk menelaah dan memahami secara mendalam fenomena politik etnisitas pada pemekaran provinsi Kotawaringin, benarkah ia dipandang sebagai instrumentalisme politik etnisitas.

\section{KAJIAN TEORITIS}

Penelitian ini menggunakan teori politik etnisitas dengan pendekatan instrumentalis dari Glazer dan Moynihan (1975). Ilmuan-ilmuan politik secara umum menyepakati bahwa etnisitas merupakan fenomena yang penting dalam kajian politik. Awalnya etnistitas melakukan pemahaman terhadap keberadaan suatu kelompok etnik. Etnik memiliki kajian yang mendalam dalam perkembangannya. Misalnya etnik dikembangkan atas dasar perasaan memiliki dalam suatu ikatan kelompok (Varshney, 2003), etnik sebagai sebuah jaringan simbol-simbol signifikan (Geertz, 1963), etnik terdiri atas pilihan kehidupan kelompok yang disebut sebagai konstruksi sosial (Benedict Anderson, 1991).

Perspektif instrumentalis memberikan penjelasan sedikit berbeda tentang etnisitas. Penjelasan itu menunjukkan sebuah cara berbeda dalam memandang formasi identitas etnis yaitu sebagai sebuah bagian dari sumberdaya politik untuk berkompetisi dalam kelompok kepentingan. Memobilisasi kelompok etnis dalam etnisitas adalah sebuah tindakan efektif menggerakkan individu untuk mencapai tujuan kolektif. Salah satu bentuk teori yang dapat menjelaskan ini adalah teori pilihan rasional. Dalam perspektif ini setiap tindakan bisa dilihat memiliki motivasi rasional sebagai dasarnya memperebutkan sumberdaya yang terbatas seperti kesejahteraan, kedudukan, kekuasaan politik ataupun kompetisi dalam memperoleh sumberdaya-sumberdaya terbatas lainnya (Yang, 2000).

Berkontradiksi dengan perspektif primordialis, perspektif instrumentalis di sini berbasis pada etnisitas dilihat secara superfisial dan keberfungsian strategisnya semata. Model ini secara mendasar sangat individualistik dan suatu ketika sangat agresif, mementingkan pribadi, rasional, pragmatis dan mungkin pula memiliki orientasi yang lebih besar. Apa yang dilakukan oleh seseorang, diasumsikan selalu rasional dan sejalan dengan apa yang mereka inginkan, dan apa yang mereka inginkan itu adalah berupa material dan kebergunaan politik untuk mereka dalam konteks kebudayaan dan situasi sejarah (N. Glazer \& Moynihan, 1975).

Dalam bukunya Beyond The Melting Pot Glazer dan Moynihan (1963)menggambarkan situasi etnisitas di New York. Kemajemukan populasi di Kota New York ialah terdiri dari kelompok identitas dari negara- 
negara yang berbeda dari seluruh dunia. Itulah sebabnya di kota tersebut terdapat kelompok komunitas dengan berbagai organisasi sosial, gereja, bahasa dan atribut budaya yang mencerminkan identitas sosiokulturalnya.

Pasca revolusi kemerdekaan, migrasi orang Inggris dan Skotlandia terjadi secara besar-besaran ke New York. Mereka ini tetap memelihara identitas kelompoknya yang memiliki leluhur yang sama yaitu orang Inggris. Pada tahun 1840 muncul pendatang Irlandia serta Jerman dan keduanya menjadi kelompok dominan di New York. Sejak tahun1855, orang Irlandia telah mencapai 28 persen dan Jerman sebesar 16 persen dari total populasi kota New York. Pendatang Yahudi dan Italia bermigrasi ke New York 1880-1924, orang Negro setelah Perang Dunia ke-I dan orang Puerto Rico setelah Perang Dunia ke-II. Kelima etnik pendatang ini menambah kemajemukan di kota New York dan bahkan disebut sebagai kota yang paling majemuk dari seluruh negara bagian Amerika Serikat.

Imigran di kota New York berasal dari orang-orang yang berbeda bahasa, agama, dialek maupun referensi pemujaan lainnya. Di sini mereka membentuk kluster-kluster berdasarkan kelompok identitas masing-masing. Lama kelamaan mereka mulai berpartisipasi dalam pembangunan kultural Amerika Serikat di New York, memiliki spesialisasi pekerjaan, makanan, musik tradisional dan bahkan tari-tarian. Jika dibeberapa tempat, imigran berasal dari satu negara, maka di New York imigran berasal dari banyak negara. Inilah keunikan New York, bahwa masyarakatnya berasal dari banyak negara yang menunjukkan adanya perbedaan bahasa, agama, kelompok kekerabatan, nilai, ide, gagasan dan pola kebudayaan.

Sejalan dengan proses asimilasi yang terjadi, imigran menyatu dengan orang Amerika. Proses ini mencakup pengaburan identitas dengan menggunakan atribut sebagaimana layaknya 'Orang Amerika' seperti gaya berpakaian, agama, berbahasa, gaya hidup, makanan dan minuman bahkan melupakan tradisi leluhurnya di tempat asal masing-masing. Pada mulanya, fenomena ini ditafsirkan sebagai cara untuk dapat 'menjadi Orang Amerika' melalui adaptasi sosiokultural yakni akulturasi dan asimilasi.

Sejak tahun 1950, lebih dari separuh populasi di kota New York adalah kelahiran kota New York. Hal ini berbeda dengan 45 tahun sebelumnya, dimana imigran massal ke kota New York adalah kelahiran negaranya masing-masing. Proses Amerikanisasi (Americanization) secara massal telah mengubah identitas kaum imigran generasi pertama di New York dan semakin menghilang pada generasi kedua. Proses inilah yang disebut oleh Glazer dan Moynihan sebagai ‘tobe a Melting Pot', yaitu semacam pengukuhan identitas sebagai orang Amerika dengan menghilangkan atribut sosiokultural.

Pada generasi pertama dan kedua imigrasi, proses Amerikanisasi terjadi guna mewujudkan mimpi 'cultural pluralism' terutama dari imigran Jerman, Irlandia, Yahudi dan Italia. Mereka ini menyatu dalam tatanan 'dunia baru' (new world) masyarakat Amerika Serikat di New York melalui Melting Pot. Pada tatanan 'dunia baru' ini setiap kelompok identitas ditransformasikan dalam pengaruh masyarakat Amerika Serikat dengan menghilangkan atribut asli sebagai imigran. Pada proses 'Melting Pot' atau 'tobe a American Population' ini, atribut sosiokultural dan sosioreligio dari negara asal dikaburkan dengan membentuk atribut baru (new atribute). Dengan serangkaian proses ini dilakukan pendatang untuk menegakkan kepentingannya pada tatanan sosial masyarakat Amerika. 
Kelompok etnik di New York bukanlah fenomena menyangkut aspek biologis tetapi terhubung dengan ikatan kepentingan. The group is not a purely biological phenomenon, but also connected by ties of interest. The ethnic groups in New York are also interest groups.

Menurut Glazer dan Moynihan, identitas etnik imigran dipergunakan bukan saja sebagai referensi personal, pandangan hidup dan sumber motivasi untuk menciptakan kohesi sosial sesama kelompok etnik imigran, tetapi sekaligus dipergunakan untuk membentuk persaudaraan berbasis ikatan kepentingan. Sederhananya, imigran yang berbeda bahasa, adat dan kultural yang menghilang pada generasi pertama dan kedua, direvitalisasi pada generasi ketiga dan berlangsung hingga kini. Ini dilakukan guna mencapai eksistensi kelompok identitas sesuai dengan situasi sosial baru yang merambah pada aspek historis, negara asal dan bahkan etnisitasnya. Tatanan baru dibentuk melalui pendirian rumah sakit, dana dan pinjaman sosial, pemukiman penduduk, lembaga amal seperti gereja maupun organisasi budaya. Akhirnya mereka dapat berhasil, sejahtera dan kaya raya sehingga keberadaannya diakui oleh pemerintah.

Dengan demikian, dalam perspektif ini etnisitas dianggap sebagai suatu sumber dan kekuatan sosial, budaya dan politik dari berbagai kelompok yang berkepentingan di dalam masyarakat. Salah satu perspektifnya adalah melihat kompetisi dari kelompok-kelompok elit dalam menguasai sumber-sumber dukungan massa sehingga memanipulasi berbagai simbol untuk memperoleh dukungan dari masyarakat. Lebih menaruh perhatian pada proses manipulasi dan mobilisasi politik ketika kelompok-kelompok sosial tersebut tersusun atas dasar atribut awal etnisitas.

\section{METODE PENELITIAN}

Penelitian ini menggunakan metodologi kualitatif dengan desain penelitian studi kasus pada wacana pemekaran Daerah Otonom Baru (DOB) provinsi Kotawaringin di Kalimantan Tengah. Pengumpulan data dilakukan dengan cara pengamatan atau observasi, penelusuran dokumen dan wawancara mendalam atau indepth interview.

Informan penelitian ini adalah Badan Pekerja Pembentukan Provinsi Kotawaringin (BP3K), Presidium Daerah Persiapan Provinsi Kotawaringin (DP2K), beberapa kepala daerah kabupaten-kabupaten pemekaran, anggota DPRD kabupaten atau provinsi, ketua-ketua Dewan Adat Dayak masing-masing kabupaten, lembaga etnik Dayak Ngaju, Ma'anyan, Bakumpai, etnik-etnik lainnya, pengusaha, dan kelompok kepentingan yang menjadi penggagas usulan pemekaran Daerah Otonom Baru Provinsi Kotawaringin.

\section{HASIL PENELITIAN DAN PEMBAHASAN}

\section{Upaya Mendorong Pemekaran Kotawaringin}

Cikal bakal pembentukan Daerah Otonom Baru (DOB) Kotawaringin telah cukup lama dibicarakan melalui berbagai seminar dan kegiatan-kegiatan ilmiah. Salah satunya yang pertama kali melakukannya adalah Ikatan Alumni dan Pelajar Kabupaten Kotawaringin Timur (HIMA KOTIM). Seminar itu digelar di Sampit Kalimantan Tengah pada 4 November 1999. Dalam seminar ini dideklarasikan pembentukan Provinsi Kotawaringin Raya dengan Sampit sebagai calon ibukotanya. Seiring waktu, wacana tersebut akhirnya menguap begitu saja. 
Atas inisiasi dari beberapa elit di wilayah Kotawaringin maka dibentuklah Badan Persiapan Pembentukan Provinsi Kotawaringin (BP3K). Badan ini bersama dengan Pemerintah Kabupaten Lamandau melaksanakan rapat koordinasi pada tanggal 10 Februari 2016. Rapat ini membahas kembali upaya pembentukan DOB Provinsi Kotawaringin Raya. Dalam rapat koordinasi ini juga membahas beberapa agenda yaitu: (1) pemilihan koordinator kepala daerah baru untuk menggantikan Mantan Bupati Kotawaringin Barat Ujang Iskandar untuk memimpin koordinasi antar kepala daerah yang akan menjadi wilayah DOB tersebut; (2) penentuan calon ibukota provinsi dan lain-lain yang dianggap perlu.

Persiapan pemekaran provinsi Kotawaringin sebenarnya sudah cukup matang. Hanya saja ketika aspirasi ini ingin dibawa kepada provinsi induk, ada semacam rasa takut tidak disetujui oleh Gubernur Teras Narang yang menjabat saat itu. Sehingga akhirnya proses ini kembali terhenti.

Hal ini sebagaimana yang ditegaskan dalam wawancara dengan Pangeran Muadjidinsjah sebagai berikut: “Kami secepatnya akan menyerahkan berkas pembentukan Provinsi baru ke Gubernur Sugianto agar bisa ditindaklanjuti. Proses ini sudah 13 tahun kami berjuang agar terbentuknya Provinsi baru ini. Sudah semua dilakukan terkait dengan persyaratannya, dari hasil kajian yang dimotori BP3K dan terdiri dari perwakilan 5 kabupaten, yakni Kabupaten Kotawaringin Timur, Seruyan, Kotawaringin Barat, Lamandau dan Sukamara, pembentukan Provinsi Kotawaringin dianggap sudah layak. Keinginan ini sudah ada sejak tahun 2006 hingga Tahun 2016 telah diupayakan keinginan rakyat lima kabupaten itu melalui Badan Pekerja Pembentukan Provinsi Kotawaringin (BP3K) dan telah mencapai akhir dengan adanya kajian akademik, hingga penentuan ibukota provinsinya"

Sempat terjadinya ketidaksepakatan terkait penentuan lokasi ibukota provinsi antara Kabupaten Kotawaringin Barat dan Kotawaringin Timur, agenda pembentukan Propinsi Kotawaringin akhirnya sempat terhenti sampai tahun 2016. Sehingga wacana pemekaran ini bukan hanya tidak sampai pada program legislasi nasional di DPR RI, tetapi juga belum masuk ke gubernur Kalimantan Tengah. Sebagai kompromi jalan tengah, akhirnya pada 2017 disepakati dengan menunjuk Kecamatan Hanau, Kabupaten Seruyan sebagai ibu kota. Kelanjutan Proses pembentukan Provinsi Kotawaringin ini telah mendapatkan restu dari Gubernur Kalimantan Tengah, dan tinggal minta persetujuan dari DPRD Provinsi Kalteng, kemudian akan dibawa ke DPR RI untuk mendapatkan persetujuannya.

Kini gubernur Kalimantan Tengah yang dijabat oleh Sugianto Sabran nampak serius untuk kembali mengangkat wacana pemekaran provinsi. Ini Sugianto Sabran tunjukkan dalam setiap kunjungannya ke wilayah lima kabupaten calon wilayah provinsi kotawaringin selalu Ia tegaskan sikapnya mendukung agenda besar ini.

Tidak hanya itu, Paman Sugianto Sabran yaitu H. Abdul Rasyid selaku penyokong utamanya di Pemilihan Kepala Daerah Provinisi Kalimantan Tengah juga memberikan perhatian serius dengan mengundang sejumlah tokoh penggagas pembentukan provinsi Kotawaringin ke kediaman pribadinya d Pangkalan Bun pada 5 Juni 2019. Melalui pertemuan ini pula digagas pemnetukan Presidium Daerah Persiapan Pemekaran Kotawaringin (DP2K).

Sejumlah tokoh dari lima kabupaten melakukan pertemuan di Sampit untuk melaksanakan Musyawarah Kerja Daerah dan Pengukuhan Presidium Daerah Persiapan Provinsi Kotawaringin. Terkendalanya 
pembentukan Provinsi Kotawaringin yang merupakan pemekaran dari Provinsi Kalimantan Tengah hingga 13 tahun disebabkan sejumlah hal. Salah satunya, ngototnya Kabupaten Kotawaringin Timur dan Kotawaringin Barat untuk menjadi ibu kota provinsi. Keberadaan Presidium DP2K juga penting untuk mempersiapkan langkah-langkah dengan melibatkan semua pihak demi percepatan pembentukan Provinsi Kotawaringin. Sebab, Provinsi Kotawaringin merupakan kehendak masyarakat lima kabupaten, bukan kehendak golongan tertentu.

Ketua Tim Formatur Presidium DP2K Dr. Rahmat Nasution Hamka menjelaskan dalam sebuah wawancara sebagai berikut: "ada beberapa pendekatan dalam proses pemekaran, yakni top down dan bottom up. Musyawarah ini terbuka bagi siapa saja, dan kami merangkul semua pihak yang ingin terlibat dalam proses pembentukan ini Bisa usulan dari pusat, bisa juga dari daerah. Bisa dua-duanya, dari masyarakat daerah maupun dari pemerintah pusat. Seperti Kalimantan Utara yang merupakan daerah perbatasan itu usulan pusat. Sedangkan di tempat kita, Provinsi Kotawaringin merupakan bottom up, atau usulan dari daerah".

Di sisi lain, BP3K selaku penggagas awal wacana Provinsi Kotawaringin ini merasa tidak dilibatkan dan ditinggalkan. Sebagaimana wawancara yang dilakukan dengan Ketua BP3K Pangeran Muadjidinsjah sebagai berikut: "Disaat semuanya sudah melangkah, justru muncul adanya pembentukan tim presidium. Kami hanya ingin agar gubernur bisa memahami apa yang menjadi aspirasi seluruh BP3K yang ada di lima kabupaten agar proses ini tetap berjalan.

Ini juga sejalan pula dengan yang disampaikan oleh Tengku Jaelani selaku Pengurus BP3K Kotawaringin Barat sebagai berikut: "kami ini sudah termakan usia, kami tidak punya kepentingan politik apapun terhadap pemekaran Provinsi Kotawaringin ini. kami hanya ingin melihat daerah ini maju, sejajar dengan daerah lainnya di Indonesia”.

Berdasarkan apa yang telah dipaparkan dapat dilihat nampaknya ada tarik-ulur kepentingan. Pertaruhan kepentingan ini yaitu antara Badan Persiapan Pembentukan Provinsi Kotawaringin (BP3K) yang diketuai Pangeran Muadjidinsjah. Berhadapan dengan Presidium Dewan Persiapan Pemekaran Kotawaringin (DP2K) yang diketuai oleh Rahmat Nasution Hamka dan didukung gubernur Kalimantan Tengah.

BP3K punya agenda yang jelas yaitu ingin menyatukan kembali daerah bekas kesultanan Kotawaringin. Para anggota BP3K terdiri dari berbagai etnik berbeda dan menyatu dalam ikatan kolektif yang sama yaitu Orang Kotawaringin. Meskipun ikatan etnisitas kolektif ini bersifat sementara, tidak kekal/temporer tapi ia telah berhasil memberikan gambaran bahwa etnisitas adalah sebuah instrumentasi untuk mencapai tujuan bersama, yaitu Pemekaran Provinsi Kotawaringin.

\section{Politik Etnisitas Menyatukan Tujuan bersama}

Keinginan dan harapan dari masyarakat lima kabupaten untuk memekarkan provinsi kotawaringin sebenarnya adalah sangat rasional. Hal ini sebagaimana yang dipaparkan oleh Fikri[14] beberapa faktor yang melatarbelakangi munculnya wacana pembentukan Provinsi Kotawaringin yaitu: (a) Luas wilayah Kalimantan Tengah yakni $153.564 \mathrm{Km} 2$ atau 1,5 kali luas Pulau Jawa. (b) Dinamika pembangunan daerah di Provinsi Kalimantan Tengah cukup lamban, karena ketersediaan infrastruktur yang kurang memadai. (c) Jarak ibukota 
Kabupaten ke ibukota Provinsi terlalu jauh, sehingga mengakibatkan pembangunan berjalan lamban, pelayanan menjadi kurang maksimal dan tidak efektif serta pengendalian dan pengawasan sulit dilakukan. (d) Kondisi penghubung antar daerah di Kalimantan Tengah tidak memadai. (e) Tidak meratanya pembangunan antara wilayah Kalimantan Tengah bagian utara dan selatan mejadikan kecemburuan di antara beberapa Kabupaten yang ada di Kalimantan Tengah. (f) 5 Kabupaten calon Provinsi Kotawaringin merupakan penyumbang terbesar APBD Kalimantan Tengah yakni 60\%. (g) Keinginan menyatukan kembali daerah kesultanan yang ada di Kalimantan Tengah.

Pada saat menemui Pangeran Muadjidinsjah beliau selalu mengatakan berulang kali tentang niat mereka untuk menyatukan kembali wilayah kesultanan Kotawaringin sebagai agenda utama pemekaran provinsi ini. berikut kutiapan wawancara dengan beliau: "kami di BP3K ini sudah tua-tua, tidak ada kepentingan politik yang kami usung. Kami hanya ingin meninggalkan jejak kepada anak cucu kami orang Kotawaringin agar menjadi provinsi sendiri terpisah dari Kalimantan Tengah. Orang Kotawaringin ini multietnis mereka yang lahir, besar, bekerja menafkahi keluarga dan menghormati adat istiadat di sini adalah orang Kotawaringin. Jadi orang Kotawaringin sendiri tidak monopoli satu etnis tertentu, kita disatukan oleh keinginan dan kepentingan yang sama. Usulan pembentukan provinsi ini tidaklah hanya untuk kepentingan golongan etnik tertentu. Lihat saja Sekjen BP3K, beliau itu aslinya orang Medan. Tapi kalau anda tanyakan dia akan menyebut dirinya orang Kotawaringin".

\section{Orang Kotawaringin Sebagai Melting Pot}

Ketika melihat rekam jejak sejarah maka kerajaan Kotawaringin adalah cabang dari keturunan Kesultan Banjar, karena keturunan Raja-raja Banjar yang pertama kali membangun Kerajaan Kotawaringin.

Sultan Musta'inubillah Raja Kerajaan Banjar berputera empat orang dan seorang putri masing-masing bernama: 1) Pangeran Adipati Tuha, Dialah yang menjadi Raja di Kerajaan Banjar bergelar Sultan Inayatullah; 2) Pangeran Adipati Anom; 3) Pangeran Antasari (Pahlawan Nasional); 4) Pangeran Adipati Antakusuma dan 5) Putri Ratu Ayu

Karena masing-masing putra mahkota berminat untuk menjadi sultan memegang tampuk pimpinan kerajaan, membuat sang ayah harus berpikir bijaksana. Putra mahkota yang berniat untuk menjadi raja, padahal Ia bukanlah seorang putra pertama, maka diputuskanlah agar Ia mengembara mencari ke beberapa wilayah baru untuk mendirikan kerajaannya sendiri. Pangeran Adipati Antakusuma, sebagai pangeran yang pemberani dan semangat yang pantang mundur untuk menjadi seorang raja, telah sungguh-sungguh bertekad untuk pergi meninggalkan Kerajaan Banjar dengan menuju ke arah barat untuk menyusuri tempat dimana akan didirikan kerajaan baru.

Atas perkenanan restu Raja dan Ratu serta pejabat-pejabat Kerajaan Banjar, Pangeran Adipati Antakusuma beserta sejumlah pengawal dan beberapa perangkat peralatan kerajaan dengan perahu layar berangkat menuju arah barat. Dalam perjalanan banyak tempat yang disinggahi antara lain Teluk Sebangau, Pagatan Mendawai, Sampit, dan Pembuang. Dikisahkan bahwa beberapa tempat-tempat yang mereka disinggahi mempunyai cerita sendiri. Pada saat mereka singgah di Teluk Sebangau, setelah beberapa hari lamanya berada rombongan mereka berada di situ, terasa masih terlalu dekat dan seakan-akan masih terdengar 
hiruk-pikuk Kerajaan Banjar atau menurut bahasa Banjar Ingauan Banjar masih kedengaran, sehingga akhirnya diputuskanlah rombongan ini untuk meninggalkan tempat tersebut. Kemudian karena hal itulah tempat itu disebut daerah Sebangau.

Dalam perjalanan selanjutnya kapal Pangeran Adipati singgah di Pagatan Mendawai. Di tempat inipun Pangeran Adipati dan rombongan merasa kurang yakin akan kondisi alam sekitarnya untuk dijadikan tempat untuk mendirikan kerajaan. Karena merasa kurang yakin (dalam bahasa Banjar Hawai) maka daerah ini diberi nama Mendawai. Begitu pula saat singgah di muara Sungai Sampit, karena dengan terasa sempit dan tidak cocok untuk mendirikan kerajaan, maka ditinggalkan lagi dan akhirnya tempat tersebut diberi nama Sampit. Bahtera Panggeran Adipati berlayar terus meninggalkan arah barat dan akhirnya singgah di Kuala Pembuang. Pada saat itu ada masyarakat di sana, tetapi kehadiran Pangeran Adipati Antakuskuma dan rombongan bermaksud untuk mendirikan kerajaan baru ditolak oleh masyarakat disana, karena mereka masih suka dipimpin oleh Kerajaan Banjar. Dengan semangat tinggi tanpa putus asa rombongan berusaha melanjutkan perjalanan, kali ini tidak lagi menyusuri pantai, tetapi menuju ke hulu sungai yang akhirnya tiba di suatu desa yang bernama Desa Pandau.

Komunitas Suku Dayak sudah lama menempati Desa Pandau yang berada di bawah kepemimpinan Demang Petinggi dari Umpang dengan tangan terbuka menerima kehadiran Pangeran Adipati Antakusuma beserta rombongan serdadunya (Info Kalteng, 2013). Demang Petinggi sebagai Kepala Suku Dayak Anom menyerukan kepada rakyatnya agar menerima rombongan Pangeran Adipati Antakusuma ini yang mana akan dijadikan raja dari rakyat Dayak dengan syarat raja harus memperlakukan kita bukan sebagai hamba, tetapi sebagai pembantu utama dan kawan yang terdekat atau sebagai saudara yang baik. Rakyat tidak akan meyembah sujud kehadapan Pangeran Adipati Antakusuma. Usul tersebut dipertimbangkan dan kemudian akhirnya diterima oleh Pangeran beserta seluruh rombongannya.

Dari pihak Suku Dayak Arut, memberikan usul agar perjanjian ini bukan perjanjian sekedar dimulut saja, melainkan harus berstempel darah manusia yang mana diambil masing-masing seorang dari Suku Dayak Arut dan seorang pula dari Pangeran Adipati Antakusuma. Hal ini sulit diterima oleh nalar manusia, hanya karena untuk sebuah perjanjian saja, tetapi karena adat Suku Dayak mendesak, maka masing-masing dari mereka menarik salah seorang diantara kedua rombongan untuk dijadikan korban.

Kedua calon korban ini tidak pernah menolak, malahan mereka menjadi bangga karena terpilih sebagai korban. Mereka diganggap sebagai kesatria dan pahlawan bangsanya. Dengan sukarela mereka dijadikan korban perjanjian setia antara kedua suku tersebut yang saling mengikat rasa kekeluargaan. Sebagai syarat kedua calon korban berdiri dan siap untuk dikorbankan, mereka masing-masing mengambil sebuah batu yang kemudian harus ditancapkan ke dalam tanah sebagai bukti turun-temurun untuk dikenang. Dengan melakukan upacara adat yang hidmat kedua calon korban berdiri di samping batu saksi, yang sekarang terkenal dengan nama "Batu Betahan" di Pandau daerah Kecamatan Arut Utara, Kabupaten Kotawaringin Barat Propinsi Kalimantan Tengah (Kotawaringin Barat, 2017).

Kemudian korban dari pihak Suku Dayak diminta berdiri menghadap ke arah hulu asal datangnya mereka serta korban yang mewakili rombongan Pangeran Adipati Antakusuma diminta berdiri menghadap hilir menunjukkan asal kedatangan mereka. Dengan sikap satria, kedua calon korban ini menunggu saat akhir 
hidupnya dengan sabar menanti sampai selesai upacara perjanjian antara kedua belah pihak. Kemudian setelah selesai upacara adat sumpah setia, Kepala Suku Dayak Arut mencabut mandaunya dan ditebaskan merobek menembus ke dada korbannya dan darah pun mengucur deras. Lalu korban yang mewakili rombongan Pangeran ditebas pula sehingga kedua darah korban ini memancar salin bersilangan lalu menetes jatuh menjadi satu membasahi tanah tersebut. Percampuran kedua darah korban ini secara langsung disaksikan seluruh rakyat kedua belah pihak, sehingga inilah yang dimaksud untuk mempersatukan segala rasa dan pikiran dalam segala rencana bersama (Kotawaringin Barat, 2017). Perjanjian ini selanjutnya dikenal "Panti Darah Janji Samaya" yang berarti perjanjian yang dikokohkan dengan tetesan darah yang menjadi satu.

Selama masanya memerintah, Pangeran Adipati Antakusuma mengangkat dan menobatkan Kyai Gede menjadi Perdana Menteri Kerajaan Kotawaringin. Kemudian untuk pertama kalinya komplek Istana Keraton Kesultanan dibangun di Kotawaringin Lama. Istana itu diberi nama Astana Alnusari. Meskipun akhirya pada tahun 1814 Keraton Kesultanan dipindahkan ke Pangkalan Bun sebagai pusat pemerintahan yang diberi nama dengan Keraton Kuning atau Indra Kencana. Setelah diproklamasikannya kemerdekaan Republik Indonesia, wilayah-wilayah Kesultanan Kotawaringin menjadi bagian wilayah Negara Kesatuan Republik Indonesia, dengan statusnya sebagai Swapraja/ Kwedanan dan kemudian akhirnya berkembang menjadi Kabupaten Daerah Tingkat II Kotawaringin Barat dinobatkan sebagai Daerah Otonom dengan Pangkalan Bun sebagai ibu kota Kabupatennya.

Sebagaimana telah dipaparkan pada bahasan sebelumnya Menurut Glazer dan Moynihan, identitas etnik pendatang dipergunakan bukan saja sebagai referensi personal, pandangan hidup dan sumber motivasi untuk menciptakan kohesi sosial sesama kelompok etnik pendatang, tetapi sekaligus dipergunakan untuk membentuk persaudaraan berbasis ikatan kepentingan. Sederhananya, pendatang yang berbeda bahasa, adat dan kultural yang menghilang pada generasi pertama dan kedua, direvitalisasi pada generasi ketiga dan berlangsung hingga kini. Ini dilakukan guna mencapai eksistensi kelompok identitas sesuai dengan situasi sosial baru yang merambah pada aspek historis, negara asal dan bahkan etnisitasnya.

Sejarah mencatat gelombang imigrasi ke Amerika dimulai sejak tahun 1492, ketika Christopher Columbus berhasil mencapai Amerika. Orang-orang Inggris lalu bermukim di Jamestown, Virginia pada tahun 1607. Permukiman ini dianggap sebagai permukiman pertama di Amerika Serikat. Selanjutnya, Amerika Serikat terus didatangi oleh orang-orang Inggris. Orang Prancis, Spanyol, dan Belanda juga bermukim di sebagian Amerika Serikat. Hingga kini, imigran-imigran yang mendiami Amerika adalah generasi yang baru dan bahkan nyaris tidak memiliki ikatan emosional dengan daerah asalnya.

Di sisi lain, penduduk di Kotawaringin sangat heterogen dan terjadi interaksi yang intens dalam jangka waktu yang sangat panjang. Sebagian besar dari pendatang yang ada di Kotawaringin lahir dan besar disana. Mereka adalah generasi yang turun-temurun berada di sana. Bahkan sebagian besar dari mereka sama halnya dengan imigran di Amerika yang sudah nyaris tidak punya ikatan emosional dengan daerah asalnya lagi. Ini dibuktikan dengan eksodusnya etnis Madura dari beberapa wilayah di Kotawaringin pada kerusuhan etnis di sana pada tahun 2001 yang justru menjadi pengungsi di Bangkalan dan Sampang. Padahal sebagaimana diketahui dari sanalah leluhur mereka berasal. 
Tatanan baru dibentuk melalui pendirian rumah sakit, dana dan pinjaman sosial, pemukiman penduduk, lembaga amal seperti gereja maupun organisasi budaya. Akhirnya mereka dapat berhasil, sejahtera dan kaya raya sehingga keberadaannya diakui oleh pemerintah.

\section{Instrumetalisme Upaya Membentuk DOB}

Tujuan utama dari adanya pemerintahan adalah memenuhi kebutuhan kesejahteraan masyarakat secara luas. Sementara pemekaran wilayah adalah salah satu cara yang bisa ditempuh untuk mencapai kesejahteraan tersebut. Mengingat luasnya wilayah Provinsi Kalimantan Tengah, maka terbentuknya Provinsi Kotawaringin adalah sebuah keniscayaan.

Meski saat ini pemerintah pusat menyatakan moratorium terhadap pemekaran daerah baru. Itu dlihat hanyalah sebuah kebijakan politik yang dapat berubah sewaktu-waktu sesuai dengan situasi dan kondisi kekinian. Ini terbukti dengan pernyataan dari Menteri Dalam Negeri Tito Karnavian yang akan memekarkan provinsi di Papua.

Dalam konteks Kotawaringin, dimana tujuan utamanya secara instrumentalis ialah identitas baru itu dibentuk untuk mendukung terlaksananya tujuan bersama yaitu pemekaran Provinsi Kotawaringin. Terlepas dari ini hanyalah identitas temporer saja hingga tujuan mereka tercapai. Justru di situlah kebaharuan yang ingin ditonjolkan dalam penelitian ini. Dengan kata lain bahwa melting pot itu bukan lagi suatu proses asimilasi dengan meleburnya setiap identitas yang ada menjadi satu identitas utama. Tetapi ia bisa saja hanya bersifat temporer atau sementara waktu hingga tujuan mereka tercapai. Ini terbukti pada kasus identitas Orang Kotawaringin di Kalimantan Tengah.

Melihat pada sejarah berdirinya provinsi Kalimantan Tengah pada tahun 1957. Nampak adanya ketidakpuasan dari kalangan elit-elit lokal di wilayah Barat (Kotawaringin) karena pemilihan ibukota Provinsi Kalimantan Tengah di Palangka Raya. Ketika masa itu, mereka mengusulkan Pangkalan Bun dan Sampit sebagai ibukota Provinsi Kalimantan Tengah. Sementara di sisi lain Kapuas mengusulkan wilayahnya yang menjadi ibukota. Perdebatan itu mereda setelah Tjilik Riwut memilih Desa Pahandut sebagai cikal bakal Kota Palangka Raya saat ini.

Sisa-sisa kekecewaan elit-elit lokal di wilayah Barat Kalimantan Tengah tersebut akhirnya kembali terangkat setelah reformasi. Terutama lagi, sejak provinsi Kalimantan Tengah terbentuk tidak pernah satu orang pun Gubernurnya yang berasal dari wilayah Barat. Karena rasa kecewa yang mendalam inilah mereka menggagas untuk memekarkan wilayah Barat menjadi provinsi baru terpisah dari Kalimantan Tengah.

Upaya pemekaran provinsi Kotawaringin sebenarnya adalah sebuah usaha yag didasari akan ketidakpuasan akan hasil pemekaran Kalimantan Tengah dari Kalimantan Selatan. Untuk mendukung agenda tersebut maka para elit-elit lokal dari wilayah barat ini akhirnya menggagas berdirinya lembaga yang bernama Badan Persiapan Pemekaran Provinsi Kotawaringin (BP3K). Lembaga sudah berdiri, tetapi itu belum cukup. Maka mereka membangun identitas yang membedakan dirinya sebagai daerah bekas Kesultanan Kotawaringin dan Orang Kotawaringin. Identitas ini lahir dan terbentuk sebagai instrumen pemersatu yang dikampayekan elit-elit lokal dari wilayah Barat di Kalimantan Tengah. 
Instrumentalisme etnisitas ini nampaknya belum berhasil untuk tujuan pemekaran daerah Provinsi Kotawaringin. Tetapi di sisi lain hal ini justru berhasil dimanfaatkan Sugianto Sabran untuk memenangkan dirinya pada Pemilukada Gubernur Kalimantan Tengah 2016 lalu. Kini Gubernur Kalimantan Tengah sudah berasal dari wilayah Barat untuk kali pertama dalam sejarah.

\section{PENUTUP}

\section{Kesimpulan}

Glazer dan Moynihan serta penelitian yang dilakukan ini memiliki kesamaan dalam dimensi ruang dan waktu. Kelompok-kelompok etnik grup tersebut berinteraksi dalam jangka waktu yang lama. Hingga sekarang yang tersisa adalah generasi ke tiga dan keempat dari gelombang imigrasi tersebut. Proses asimilasi tersebut baik yang terjadi secara alami maupun atas campur tangan pemerintah melalui program transmigrasi.

Meskipun begitu, Beyond the Melting Pot dari Glazer dan Moynihan berbeda dalam asimilasi. Di mana menyatunya kelompok-kelompok etnik grup menjadi being amerika bersifat kekal. Sementara di sisi lain asimilasi etnik-etnik grup menjadi orang Kotawaringin hanya temporer dan berlaku diruang dan waktu tertentu dalam konteks ini untuk keperluan pemekaran saja.

Perbedaan berikutnya yaitu pada locus yang dijadikan lokasi, di mana Glazer dan Moynihan melihat lebih pada nation state building di Amerika. Ini dalam upaya membentuk karakter inti bangsa Amerika yang lahir di sana. Di Kotawaringin berbeda karena yang mereka bangun bukan nations state building, tetapi lebih pada instrumen pemersatu untuk mencapai tujuan bersama yang ingin mereka capai yaitu pemekaran Provinsi Kotawaringin

\section{Saran}

Saat ini Kementerian Dalam Negeri Republik Indonesia setidaknya menerima 315 usulan pemekaran daerah. Masing-masing daerah mempunyai berbagai permasalahan yang menjadi penghambat. Salah satunya seperti tarik-ulur kepentingan antar etnis yang heterogen di daerah tersebut. Solusi yang dapat diambil adalah membangun identitas kolektif seperti yang terjadi di Kotawaringin.

\section{DAFTAR PUSTAKA}

Benedict Anderson. (1991). Imagined Communities: Refelctions on the origin and spread nationalism. In Verso. https://doi.org/10.4324/9780203358672_Imagined_communities

Canessa, A. (2014). Conflict, claim and contradiction in the new 'indigenous' state of Bolivia. Critique of Anthropology, 34(2), 153-173. https://doi.org/10.1177/0308275X13519275

Escárcega, S. (2010). Authenticating strategic essentialisms: The politics of indigenousness at the united nations. Cultural Dynamics, 22(1), 3-28. https://doi.org/10.1177/0921374010366780

Geertz, C. (1963). The integrative revolution: primordial sentiments and politics in the new states. Old Societies and New States: The Quest for Modernity in Asia and Africa. https://doi.org/The Free Press of Gelncoe 
Glazer, N. and D. P. M. (1963). Beyond the Melting Pot, Revised, Second Edition The Negroes, Puerto Ricans, Jews, Italians, and Irish of New York City. Retrieved from https://mitpress.mit.edu/books/beyondmelting-pot

Glazer, N., \& Moynihan, D. P. (1975). Introduction. Ethnicity: \{Theory\} and \{Experience\}.

Hale, H. E. (2008). The foundations of ethnic politics: Separatism of states and nations in Eurasia and the world. In The Foundations of Ethnic Politics: Separatism of States and Nations in Eurasia and the World. https://doi.org/10.1017/CBO9780511790669

Hill, J., \& Wilson, T. (2003). Identity politics and the politics of identities. Identities, 10(1), 1-8. https://doi.org/10.1080/10702890304336

Huntington, S. P. (1997). The Clash of Civilizations and the Remaking of World Order by Samuel P. Huntington:The Clash of Civilizations and the Remaking of World Order. American Journal of Sociology. https://doi.org/10.1086/231221

Info Kalteng. (2013). Sejarah Kabupaten Kotawaringin Barat. Retrieved November 16, 2019, from https://informasikalteng.blogspot.com/2013/06/sejarah-kabupaten-kotawaringin-barat.html.

Kambo, A. G. (2007). Politik Identitas: Studi Kualitatif Tentang Konstruksi Identitas Politik Etnik Mandar. Disertasi pada Program Doktor Ilmu Sosial. Surabaya.

Kotawaringin Barat. (2017). Sejarah Kabupaten Kotawaringin Barat. Retrieved November 16, 2019, from https://site.kotawaringinbaratkab.go.id/page/1/sejarah-singkat.

Narang, A. T. (2004). Pemilihan Kepala Daerah Secara Langsung dan Pengaturan Pemerintahan Daerah Berdasarkan Undang-undang No. 32 Tahun 2004 Tentang Pemerintahan Daerah. Jakarta: ATN Centre.

Prasetyo, B. (2014). 'Birokrasi Responsif dalam Local-Good Governance'. Disampaikan pada Pidato Pengukuhan Jabatan Guru Besar dalam Bidang Ilmu Politik Lokal FISIP Universitas Airlangga Surabaya. Sabtu, 13 September 2014. tidak diterbitkan.

Qodir, Z. (2012). Involusi Politik Pemekaran, Etnisitas, dan Agama: Tantangan Reformasi Birokrasi Kasus Maluku Utara. Jurnal Bina Praja, 4(4), 217-226. https://doi.org/http://dx.doi.org/10.21787/jbp.4.2012.217-226

Schulte Nordholt, H., \& Klinken, van. (2007). Renegotiating boundaries: local politics in post-Suharto Indonesia. Renegotiating Boundaries: Local Politics in Post-Suharto Indonesia. https://doi.org/10.26530/oapen_376972

Simanjuntak, B. A. et al. (2010). Otonomi Daerah, Etnonasionalisme dan Masa Depan Indonesia: Berapa Persen Lagi Tanah Dan Air Milik Rakyat. Jakarta: Yayasan Pustaka Obor Indonesia.

Varshney, A. (2003). Nationalism, Ethnic Conflict, and Rationality. Perspectives on Politics. https://doi.org/10.1017/S1537592703000069

Yang, P. Q. (2000). Ethnic Studies: Issues and Approaches. New York: State University of New York Press.

Zulfauzan, R. (2018, July 28). Quo Vadis Provinsi Kotawaringin. Berita Sampit. Retrieved from https://beritasampit.co.id/2018/07/28/quo-vadis-provinsi-kotawaringin/ 